\title{
Unusual presentation of spinal lipomatosis
}

This article was published in the following Dove Press journal:

International Medical Case Reports Journal

23 September 2014

Number of times this article has been viewed

\author{
William Stephenson' \\ Matthew J Kauflinn 2,3 \\ 'Primary Care, Huntington \\ Veteran's Affairs Medical Center, \\ Huntington, WV, USA; ${ }^{2}$ Department \\ of Pharmacy, Grandview Medical \\ Center, Dayton, Ohio, OH, USA; \\ ${ }^{3}$ Ohio Northern University, Ada, \\ Ohio, OH, USA
}

\begin{abstract}
Spinal epidural lipomatosis (SEL) is a rare condition characterized by overgrowth of normal adipose tissue in the extradural space within the spinal canal that can lead to significant spinal cord compression. It is most commonly reported in patients receiving chronic glucocorticoid therapy. Other causes can include obesity and hypercortisolism. Occasionally, idiopathic SEL will occur in patients with no known risk factors, but cases are more generally reported in obesity and males. We present the case of a 35 year-old non-obese woman found to have rapidly progressive SEL that was not associated with any of the common causes of the disorder.
\end{abstract}

Keywords: lipomatosis, laminectomy, hypercortisolism

\section{Introduction}

Spinal epidural lipomatosis (SEL) leads to accumulation of adipose tissue within the spinal canal. The excessive fat depositions associated with SEL may cause direct mechanical compression of the spinal cord or nerve roots involving the lumbar and thoracic spine. ${ }^{1,2}$ It is most frequently seen in patients exposed to chronic glucocorticoid therapy and typically presents as back pain, radiculopathy, claudication, and paraparesis. ${ }^{3}$ Diagnosis of SEL remains challenging and typically involves computed tomography or magnetic resonance imaging (MRI) to rule out other conditions such as spinal tumors, spinal abscess, hematoma, disc prolapse, and demyelinating diseases. MRI is the most sensitive and specific test for assessing adipose tissue and it may also suggest the histological nature of the compressive lesion. ${ }^{4-6}$ The treatment approach depends on the severity of the symptoms and the related neurological impairment. Conservative management is indicated for mild symptoms, and consists of weight reduction, tapering of exogenous steroids, and physical therapy. In patients with debilitating symptoms, decompression is achieved through laminectomy and debulking of the hypertrophied epidural fat. ${ }^{4,7}$ We present the case of a 35 year-old woman who, after hospital admission, developed progressive neurological impairment related to idiopathic SEL.

\section{Report of case}

A 35 year-old African American woman with a past medical history of type 1 diabetes mellitus and end stage renal disease presented to our emergency room via ambulance after being found unresponsive by her boyfriend at home. The patient had recent complaints of lower extremity weakness and denied use of glucocorticosteroids in the past. Her admission weight was $61 \mathrm{~kg}$, and her height was $152 \mathrm{~cm}$ (body mass
Correspondence: William Stephenson 2004 Donald Avenue, Huntington, WV 2570I, USA

$\mathrm{Tel}+\mathrm{I} 5 \mathrm{I} 34464742$
International Medical Case Reports Journal 20|4:7 |39-|4| permission from Dove Medical Press Limited, provided the work is properly attributed. Permissions beyond the scope of the License are administered by Dove Medical Press Limited. Information on how to request permission may be found at htrp://www doverpess 
index [BMI]: $26.4 \mathrm{~kg} / \mathrm{m}^{2}$ ). Unfortunately, serum cortisol levels were not measured during this admission. The patient was initially admitted to our medical intensive care unit with a diagnosis of bacteremia and was found to have a methicillin-sensitive Staphylococcus aureus tricuspid valve endocarditis. After initial stabilization, and treatment of her infection, the patient complained of the inability to stand or ambulate, especially on her right side. MRI without contrast of the thoracic spine showed extensive epidural fat, consistent with lipomatosis, extending from T1 through T9 (Figure 1). MRI with contrast of the thoracic spine confirmed this and failed to show any evidence of epidural abscess. MRI of the cervical and lumbar spine was unremarkable. At this point, a posterior decompression laminectomy was performed from T3 through T7. During surgery, a very large compressive epidural lipomatosis was visualized. The most significant spinal cord compression was seen at levels T4 through T6. Pathology of the specimen failed to show malignancy and was reported as adipose tissue. Following surgery the patient was eventually transferred to a rehabilitation hospital, where she continued to improve her functional status. The patient continued to improve and was ambulating at follow-up 11 months later.

\section{Comment}

SEL is a rare condition first diagnosed in 1975. Currently, the underlying pathogenesis of SEL is unknown. One proposed mechanism implies that elevated levels of cortisol lead to

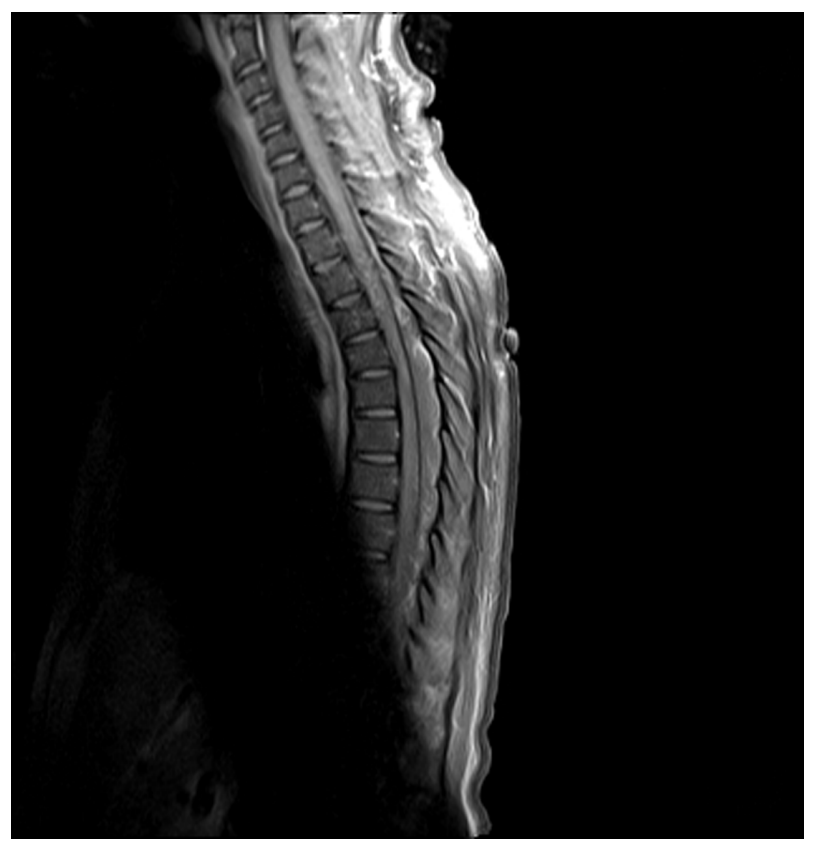

Figure I Patient's MRI showing lipomatosis extending from TI through T9. hypertrophy of adipose tissue that is already present in the extradural space of the thoracic and lumbosacral spine. ${ }^{2,8}$ Despite this, approximately $17 \%$ of cases are idiopathic. ${ }^{9}$ Typically, males are more commonly affected than females. The clinical manifestations of this disease depend greatly on the level of canal compromise. It has been reported that SEL of the thoracic levels causes myelopathy while SEL at the lumbar levels results in radiculopathy. The manifestations of this disorder can also mimic other conditions such as: spinal tumors, spinal abscess, hematoma, and demyelinating conditions. Treatment of this disorder usually begins with conservative measures such as weight loss along with steroid tapering and analgesics. However, in patients who present with signs or symptoms of spinal compression, the recommended first line treatment is surgical decompression. This procedure has been shown to be effective in a large percentage of case reports for symptomatic relief. ${ }^{3}$ Our case is unusual in that it arose in a non-obese female patient, with no known glucocorticoid exposure and rapid symptom progression. This led to a decompressive laminectomy prior to trial of conservative treatments secondary to the presence of spinal cord compression. This spinal cord compression was established by MRI and later confirmed via operative visualization. A second surgical option available instead of laminectomy would be the re-insertion of the lamina with titanium miniplates. This procedure has shown decreased postoperative deformities. However, the rate of postoperative deformity is low; especially when more than $50 \%$ of facet joints are left intact. ${ }^{10}$

\section{Conclusion}

SEL is a rare condition that can lead to severe physical and functional limitation. This condition is usually associated with a male predisposition and steroid use or hypercortisolism. Conservative initial therapy consists of physical rehabilitation along with weight loss. However, if conservative measures fail, surgical decompression is indicated. SEL should be considered in the evaluation of patients with low back pain, persistent radicular pain and progressive myelopathy, particularly in obese patients or those with chronic steroid exposure.

\section{Disclosure}

The authors report no conflicts of interest for this manuscript.

\section{References}

1. López-González A, Resurrección Giner M. Idiopathic spinal epidural lipomatosis: urgent decompression in an atypical case. Eur Spine J. 2008;17(Suppl 2):S225-S227. 
2. Alvarez A, Induru R, Lagman R. Considering symptomatic spinal epidural lipomatosis in the differential diagnosis. Am J Hosp Palliat Care. 2013;30(6):617-619.

3. Chen CC, Lee WY, Cho DY. Spinal epidural lipomatosis. Zhonghua Yi Xue Za Zhi (Taipei). 2002;65(2):86-89.

4. Fogel GR, Cunningham PY 3rd, Esses SI. Spinal epidural lipomatosis: case reports, literature review and meta-analysis. Spine J. 2005;5(2):202-211.

5. Pinkhardt EH, Sperfeld AD, Bretschneider V, Unrath A, Ludolph AC, Kassubek J. Is spinal epidural lipomatosis an MRI-based diagnosis with clinical implications? A retrospective analysis. Acta Neurol Scand. 2008;117(6):409-414.

6. Ishikawa Y, Shimada Y, Miyakoshi N, et al. Decompression of idiopathic lumbar epidural lipomatosis: diagnostic magnetic resonance imaging evaluation and review of the literature. J Neurosurg Spine. 2006;4(1):24-30.
7. Wälchli B, Benini A. Spinal epidural lipomatosis. Swiss Med Wkly. 2001;131(23-24):359.

8. Choi KC, Kang BU, Lee CD, Lee SH. Rapid progression of spinal epidural lipomatosis. Eur Spine J. 2012;21 Suppl 4:S408-S412.

9. Al-Khawaja D, Seex K, Eslick GD. Spinal epidural lipomatosis - a brief review. J Clin Neurosci. 2008;15(12):1323-1326.

10. Medscape [homepage on the Internet]. Schatio B, Pluta RM, Schaller K. Laminoplasty; [updated June 21, 2012]. Available from: http:// emedicine.medscape.com/article/1890493-overview. Accessed December 8, 2013.

\section{Publish your work in this journal}

The International Medical Case Reports Journal is an international, peer-reviewed open-access journal publishing original case reports from all medical specialties. Previously unpublished medical posters are also accepted relating to any area of clinical or preclinical science. Submissions should not normally exceed 2,000 words or
4 published pages including figures, diagrams and references. The manuscript management system is completely online and includes a very quick and fair peer-review system, which is all easy to use. Visit http://www.dovepress.com/testimonials.php to read real quotes from published authors.

Submit your manuscript here: http://www.dovepress.com/international-medical-case-reports-journal-journal 